\title{
Use of electronic cigarettes and secondhand exposure to their aerosols are associated with asthma symptoms among adolescents: a cross-sectional study
}

\author{
Abdullah Alnajem ${ }^{1 \dagger}$, Abdullah Redha ${ }^{1 \dagger}$, Dalal Alroumi ${ }^{1}$, Ahmed Alshammasi ${ }^{1}$, Mohamad Ali ${ }^{1}$, \\ Maram Alhussaini ${ }^{1}$, Waad Almutairi ${ }^{1}$, Ali Esmaeil ${ }^{1}$ and Ali H. Ziyab ${ }^{2^{*}}$ (1)
}

\begin{abstract}
Background: Globally, a surge in electronic cigarette (e-cigarette) use has been observed in recent years, with youth being the most susceptible group. Given their recent emergence, studies assessing the health consequences of using e-cigarettes and exposure to their secondhand aerosols (SHA) are limited. Hence, this study sought to assess associations between e-cigarette use and household exposure to SHA from e-cigarettes with asthma symptoms among adolescents.

Methods: A school-based cross-sectional study was conducted by enrolling high school students $(n=1565$; aged 16-19 years) in Kuwait. Participants self-completed a questionnaire on tobacco products use (e-cigarettes and cigarettes) and asthma symptoms. Current e-cigarette use and cigarette smoking were defined as any use in the past 30 days. Household exposure to SHA from e-cigarettes in the past 7 days was reported as none (0 days), infrequent ( $1-2$ days), and frequent ( $\geq 3$ days). Asthma symptoms included current (past 12 months) wheeze, current asthma (history of clinical diagnosis and current wheeze and/or medication use), and current symptoms of uncontrolled asthma ( $\geq 4$ attacks of wheeze, $\geq 1$ night per week sleep disturbance from wheeze, and/or wheeze affecting speech). Associations were assessed using Poisson regression with robust variance estimation, and adjusted prevalence ratios (aPRs) and 95\% confidence intervals (Cls) were estimated.
\end{abstract}

Results: Among the analytical study sample $(n=1345)$, current e-cigarette use and cigarette smoking was reported by $369(27.4 \%)$ and 358 (26.6\%) participants, respectively. Compared to never e-cigarette users and never cigarette smokers, current e-cigarette users with no history of cigarette smoking had increased prevalence of current wheeze $(a P R=1.54,95 \% \mathrm{Cl} 1.01-2.45)$ and current asthma $(a P R=1.85,95 \% \mathrm{Cl} 1.03-3.41)$. Moreover, the frequency of exposure to household SHA from e-cigarettes was associated with asthma symptoms. For example, compared to those with no exposure to household SHA, frequent exposure to household SHA was associated with current wheeze (aPR $=1.30$, $95 \% \mathrm{Cl} 1.04-1.59)$, current asthma $(\mathrm{aPR}=1.56,95 \% \mathrm{Cl} 1.13-2.16)$, and current uncontrolled asthma symptoms $(\mathrm{aPR}=1.88,95 \% \mathrm{Cl} 1.35-2.62)$.

\footnotetext{
*Correspondence: aziyab@hsc.edu.kw

${ }^{\dagger}$ Abdullah Alnajem and Abdullah Redha contributed equally to this work

${ }^{2}$ Department of Community Medicine and Behavioral Sciences, Faculty

of Medicine, Kuwait University, Kuwait City, Kuwait

Full list of author information is available at the end of the article
}

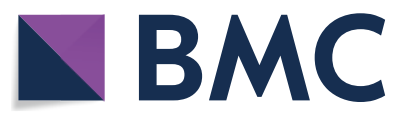

(c) The Author(s) 2020. Open Access This article is licensed under a Creative Commons Attribution 4.0 International License, which permits use, sharing, adaptation, distribution and reproduction in any medium or format, as long as you give appropriate credit to the original author(s) and the source, provide a link to the Creative Commons licence, and indicate if changes were made. The images or other third party material in this article are included in the article's Creative Commons licence, unless indicated otherwise in a credit line to the material. If material is not included in the article's Creative Commons licence and your intended use is not permitted by statutory regulation or exceeds the permitted use, you will need to obtain permission directly from the copyright holder. To view a copy of this licence, visit http://creativecommons.org/licenses/by/4.0/. The Creative Commons Public Domain Dedication waiver (http://creativeco mmons.org/publicdomain/zero/1.0/) applies to the data made available in this article, unless otherwise stated in a credit line to the data. 
Conclusions: E-cigarette use and their household SHA exposure were independently associated with asthma symptoms among adolescents. Hence, such observations indicate that e-cigarette use and passive exposure to their aerosols negatively impact respiratory health among adolescents.

Keywords: Electronic cigarettes, Vaping, Combustible cigarettes, Asthma, Respiratory symptoms, Adolescents, Kuwait

\section{Introduction}

Electronic cigarettes (e-cigarettes; also known as vaping) have rapidly emerged and became the most used tobacco product among youth in many regions of the world. For instance, among high school students in the United States (US), the prevalence of current (past 30-day) use of e-cigarettes increased from $11.7 \%$ in 2017 to $27.5 \%$ in 2019, making e-cigarettes the most commonly used tobacco product $[1,2]$. Similarly, the prevalence of e-cigarette use among adolescents aged 16-19 years in Canada has increased from $8.4 \%$ in 2017 to $14.6 \%$ in 2018 , whereas there was no apparent change in e-cigarette use among adolescents in England (8.7\% in 2017 to 8.9\% in 2018) [3]. Globally, there is a considerable heterogeneity in the prevalence of e-cigarette use between and within nations, with a general trend of increase in use among youth [4].

The recent surge in e-cigarette use among youth has become a major global public health concern. Reports have shown that e-cigarette use is associated with subsequent use of combustible cigarettes [5-8]; hence, undermining the decades-long progress in reducing smoking among youth [9]. Moreover, observational studies have shown that e-cigarette use is associated with increased risk of marijuana use among adolescents $[10,11]$. In regard to acute health effects, the use of e-cigarettes has been linked with a recent outbreak of severe pulmonary injuries and deaths in the US (e-cigarette, or vaping, product use-associated lung injury [EVALI]) that are strongly associated with vaping tetrahydrocannabinol (THC), the main psychoactive compound in cannabis $[12,13]$.

Aerosols (vapor) emitted by e-cigarettes contain ultrafine particles, such as volatile carbonyls, reactive oxygen species, furans, formaldehyde, and metals (cadmium, lead, nickel, tin, copper, chromium) [14, 15]. Given such constituents, primary or secondary exposure to e-cigarettes aerosols might be associated with health risks. In vitro studies demonstrated that e-cigarette liquids and aerosols cause cytotoxicity in various cell lines, leading to cell death, decreased cell proliferation, and increased oxidative stress $[15,16]$. In vivo animal studies showed that inhalation of e-cigarette aerosols lead to airway inflammation, reduced lung function, and impaired innate immunity $[15,16]$. In humans, a report showed that airborne nicotine concentrations were higher in homes where e-cigarette use is allowed compared to smoke-free and e-cigarette-free homes, and this observation was further supported by showing that salivary and urinary cotinine levels were higher among non-smokers who were passively exposed to household secondhand aerosols (SHA) compared to non-smokers living in homes with no SHA and secondhand smoke (SHS) exposure [17].

A limited number of population-based studies investigating associations between e-cigarette use and exposure to SHA from e-cigarettes with respiratory symptoms exist $[14,16,18,19]$. Emerging epidemiological studies have demonstrated positive associations between e-cigarette use and respiratory symptoms [20-30]. A prior study showed that exposure to SHA from e-cigarettes is associated with asthma exacerbations among youth with asthma [31]; however, little is known on whether exposure to SHA from e-cigarettes is associated with respiratory symptoms. Given the scarcity of investigations and the need to better understand the health effects of e-cigarettes, the present study aimed to assess associations between e-cigarette use and exposure to household SHA from e-cigarettes with asthma symptoms (current wheeze, current asthma, and current uncontrolled asthma symptoms) among adolescents.

\section{Methods}

\section{Study setting, design, and participants}

Geographically, Kuwait is divided into six governorates, and the school districts follow a similar geographic distribution. Education in Kuwait is mainly provided by free public schools funded by the state and, to a lesser extent, by private schools. The education system can be divided into four stages, namely, kindergarten, elementary school (1st-5th grade), middle school (6th-9th grade), and high school (10th-12th grade), and in the latter three stages, the students are segregated by sex. Schooling is compulsory for all children aged 6 to 14 years.

This cross-sectional study enrolled schoolchildren $(\mathrm{n}=1565)$ attending public high schools (11th and 12th grade) throughout the State of Kuwait, which included children aged between 16 and 19 years. The schoolchildren were enrolled in the study during the second semester of the 2018-2019 school year (January to May 2019). A stratified two-stage cluster sampling method was used to select a representative study sample of schoolchildren 
from a random sample of schools. At the time the study was initiated, there were 139 public high schools in Kuwait enrolling approximately 60,663 students $(26,692$ males and 33,971 females). From a list obtained from the Ministry of Education, Kuwait, of all public high schools stratified by school district and sex, schools were randomly selected using randomly generated numbers. Proportional allocation was used to determine the number of participants needed from each school district by estimating sex-stratified weights relative to the student body size in each given school district. In total, 14 schools served as the recruitment venues for enrolling the required sample size. The study was approved by the Health Sciences Center Ethics Committee for Student Research at Kuwait University (No. 750). Written informed assent was obtained from each participating student. As per the waiver obtained from the Ethics Committee, no consents were sought from the parents.

\section{Questionnaire and variable definitions}

The participants self-completed the study-specific questionnaire that adapted questions from the National Youth Tobacco Survey (NYTS) [2] and the International Study of Asthma and Allergies in Childhood (ISAAC) [32] questionnaires. The questionnaire gathered information on demographic data, e-cigarette use, combustible cigarette use, exposures to SHS and SHA from e-cigarettes, and clinical history and symptoms of asthma.

Never, ever, and current (past 30-day) use of e-cigarettes and combustible cigarettes was ascertained. Participants who reported that they have never used e-cigarettes/combustible cigarettes, even once or twice, were classified as "never users". Participants who reported ever using e-cigarettes/combustible cigarettes, but not in the past 30 days, were classified as "former users". Participants who reported using e-cigarettes/combustible cigarettes on $\geq 1$ day during the past 30 days were classified as "current users". Moreover, the frequency of exposure to household SHS and SHA in the past 7 days was assessed by asking: "During the past 7 days, on how many days did someone smoke tobacco products in your home while you were there?" and "During the past 7 days, on how many days did someone smoke e-cigarettes in your home while you were there?" While the frequency of exposure to SHS and/or SHA in public places was assessed by asking: "During the past 7 days, on how many days were you exposed to the smoke of tobacco products or e-cigarettes in public places (e.g., school, restaurants, coffee shops, etc.)?". These variables were categorized as "no exposure (0 days)", "infrequent exposure (1-2 days)", and "frequent exposure ( $\geq 3$ days)".

Asthma symptoms were defined according to the ISAAC methodology [33]. Current wheezing was ascertained by asking the following question: "Have you had wheezing or whistling in the chest in the past 12 months?" Current asthma (i.e., active asthma in the past 12 months) was defined by an affirmative response to the items "history of doctor-diagnosed asthma" and "wheezing in the past 12 months" and/or "asthma treatment in the past 12 months". Symptoms of severe asthma included the presence of current wheezing and the occurrence of $\geq 4$ wheezing attacks, sleep disturbance from wheezing $\geq 1$ night per week, and/or wheezing-affected speech in the past 12 months. Although the ISAAC methodology referred to the aforementioned manifestations as "symptoms of severe asthma", such features might be better described as "uncontrolled asthma symptoms" that can be considered as signs of more severe disease $[34,35]$. Hence, the term "uncontrolled asthma symptoms" was used in this article.

\section{Statistical analysis}

All statistical analyses were carried out using SAS 9.4 (SAS Institute, Cary, North Carolina, USA). The statistical significance level was set at $\alpha=0.05$ for all association analyses. Descriptive analyses were carried out to determine the frequencies and proportions of categorical variables. To determine whether the analytical study sample $(n=1345$; sample of participants with complete information on status of electronic cigarettes use, cigarette smoking, current wheeze, current asthma, and current uncontrolled asthma symptoms) was representative of the total enrolled study sample $(n=1565)$, we compared proportions of categorical variables across these two samples using chi-square $\left(x^{2}\right)$ tests.

Adjusted associations were assessed by applying a modified Poisson regression with robust variance estimation using the GENMOD procedure in SAS 9.4 to estimate and infer the adjusted prevalence ratios (aPRs) and their 95\% confidence intervals (CIs). When assessing associations between e-cigarette use (exposure variable) and asthma symptoms (outcome variable), we further classified never, former, and current e-cigarette users according to their combustible cigarette use status (never, former, and current). Hence, nine mutually exclusive groups were defined: "never cigarette smoker and never e-cigarette use", "never cigarette smoker and former e-cigarette use", "never cigarette smoker and current e-cigarette use", "former cigarette smoker and never e-cigarette use", "former cigarette smoker and former e-cigarette use", "former cigarette smoker and current e-cigarette use", "current cigarette smoker and never e-cigarette use", "current cigarette smoker and former e-cigarette use", and "current cigarette smoker and current e-cigarette use". In the regression analysis, the "never cigarette smoker and never e-cigarette use" 
group was used as the common reference. In assessing association between frequency of exposure to household SHA from e-cigarettes (exposure variable) and asthma symptoms (outcome variables), the "no exposure (0 days)" was used as the common reference.

\section{Results}

In total, 1575 high school students (732 boys and 843 girls) were invited to participate, and 1565 (729 boys and 836 girls) were enrolled in the study (response proportion: $99.4 \%)$. Basic characteristics of the total study sample $(n=1565)$ and the analytical study sample $(n=1345)$ are presented in Table 1 . The analytical study sample

Table 1 Characteristics of total enrolled study sample and analytical study sample

\begin{tabular}{|c|c|c|}
\hline Variables & Total study sample $(n=1565)$ & $\begin{array}{l}\text { Analytical } \\
\text { study sample* } \\
(n=1345)\end{array}$ \\
\hline \multicolumn{3}{|l|}{ Sex, n (\%) } \\
\hline Female & $836(53.4)$ & $697(51.8)$ \\
\hline Male & $729(46.6)$ & $648(48.2)$ \\
\hline \multicolumn{3}{|l|}{ Age groups, n (\%) } \\
\hline$\leq 16$ years & $386(25.1)$ & $336(25.4)$ \\
\hline 17 years & $843(54.7)$ & $712(53.8)$ \\
\hline$\geq 18$ years & $311(20.2)$ & $276(20.8)$ \\
\hline Missing, $\mathrm{n}$ & 25 & 21 \\
\hline \multicolumn{3}{|l|}{ Electronic cigarette use, n (\%) } \\
\hline Never & $957(61.9)$ & $812(60.4)$ \\
\hline Former & $182(11.8)$ & $164(12.2)$ \\
\hline Current (any use in past 30 days) & $408(26.3)$ & $369(27.4)$ \\
\hline Missing, $\mathrm{n}$ & 18 & 0 \\
\hline \multicolumn{3}{|l|}{ Cigarette smoking, n (\%) } \\
\hline Never & $870(56.5)$ & $743(55.3)$ \\
\hline Former & $278(18.1)$ & $244(18.1)$ \\
\hline Current (any use in past 30 days) & $391(25.4)$ & $358(26.6)$ \\
\hline Missing, $\mathrm{n}$ & 26 & 0 \\
\hline \multicolumn{3}{|c|}{ Household secondhand aerosol in past 7 days, n (\%) } \\
\hline None (0 days) & $1015(67.9)$ & $882(67.0)$ \\
\hline Infrequent ( $1-2$ days) & $144(9.6)$ & $128(9.7)$ \\
\hline Frequent ( $\geq 3$ days) & $336(22.5)$ & $306(23.3)$ \\
\hline Missing, $n$ & 70 & 29 \\
\hline \multicolumn{3}{|c|}{ Household secondhand smoke in past 7 days, $\mathrm{n}(\%)$} \\
\hline No exposure (0 days) & $876(58.1)$ & $758(57.5)$ \\
\hline Infrequent exposure ( $1-2$ days) & $146(9.7)$ & $127(9.6)$ \\
\hline Frequent exposure ( $\geq 3$ days) & $486(32.2)$ & $433(32.9)$ \\
\hline Missing, $\mathrm{n}$ & 57 & 27 \\
\hline \multicolumn{3}{|l|}{ Current wheeze, $n(\%)$} \\
\hline Yes & $385(28.1)$ & $381(28.3)$ \\
\hline Missing, $\mathrm{n}$ & 195 & 0 \\
\hline \multicolumn{3}{|l|}{ Current asthma, n (\%) } \\
\hline Yes & $246(16.1)$ & $242(18.0)$ \\
\hline Missing, $\mathrm{n}$ & 38 & 0 \\
\hline \multicolumn{3}{|c|}{ Current uncontrolled asthma symptoms, n (\%) } \\
\hline Yes & $227(16.6)$ & $225(16.7)$ \\
\hline Missing, $n$ & 195 & 0 \\
\hline
\end{tabular}

* Refers to a sample of participants with complete information on status of electronic cigarettes use, cigarette smoking, current wheeze, current asthma, and current uncontrolled asthma symptoms (i.e., excluding 220 participants with incomplete information) 
and the total study sample were similar in all characteristics investigated. Of the analytical study sample, $51.8 \%$ $(697 / 1345)$ were females and $53.8 \%(712 / 1324)$ were 17 years old.

Of the analytical study sample, current use of e-cigarettes was reported by $27.4 \%$ (369/1345), current combustible cigarette smoking was reported by $26.6 \%$ (358/1345), and frequent exposure to household SHA from e-cigarettes was reported by $23.3 \%$ (306/1316). In regard to asthma symptoms, prevalence estimates of current wheeze, current asthma, and current uncontrolled asthma symptoms were $28.3 \%$ (381/1345), $18.0 \%$ (242/1345), and $16.7 \%$ (225/1345), respectively (Table 1$)$.

Associations between e-cigarette use and asthma symptoms are shown in Table 2. Compared to the "never cigarette smoker and never e-cigarette use" group, those who are in the "never cigarette smoker and current e-cigarette use" group (i.e., independent effect of e-cigarettes) had statistically significantly increased prevalence of current wheeze ( $\mathrm{aPR}=1.54,95 \% \mathrm{CI} 1.01-2.45)$ and current asthma $(\mathrm{aPR}=1.85,95 \% \mathrm{CI} 1.03-3.41)$, and a nonstatistically significant trend of increased prevalence of current uncontrolled asthma symptoms $(\mathrm{aPR}=1.56,95 \%$ CI 0.80-3.06). Hence, these results indicate that current e-cigarette use is associated with asthma symptoms independent of cigarette smoking and other potential confounders (i.e., sex, age, and exposure to household and public places SHS and SHA). Similarly, those who are in the "former cigarette smoker and current e-cigarette use" group had an increased prevalence of the assessed asthma symptoms compared to the reference group.
Current cigarette smoking was associated with current wheeze and current asthma independent of e-cigarette use status. For instance, "current cigarette smoke and never e-cigarette use" group (i.e., independent effect of cigarette smoking) had 1.64-fold (95\% CI 1.06-2.55) higher prevalence of wheeze compared to the reference group (Table 2). Dual users of e-cigarettes and cigarettes compared to none users of either product demonstrated the strongest associations with asthma symptoms prevalence. For instance, those in the "current cigarette smoker and current e-cigarette use" group had 1.97times (95\% CI 1.35-2.88) increased prevalence of current uncontrolled asthma symptoms compared to "never cigarette smoker and never e-cigarette use" group (Table 2).

Associations between frequency of exposure to household SHA from e-cigarettes in the past 7 days with asthma symptoms are presented in Table 3. Frequent exposure ( $\geq 3$ days) to house SHA demonstrated associations with all assessed asthma symptoms. For example, compared to those with no exposure to household SHA, infrequent exposure was associated with a 1.17 -times (95\% CI 0.87-1.58) higher prevalence of current wheeze, whereas frequent exposure was associated with a 1.30 -times (95\% CI 1.04-1.59) higher prevalence of current wheeze. Similarly, those who reported frequent household SHA exposure had highest prevalence of current asthma $(\mathrm{aPR}=1.56,95 \% \mathrm{CI}$ 1.13-2.16) and current uncontrolled asthma symptoms (aPR $=1.88,95 \%$ CI 1.35-2.62) compared to those who reported no household SHA exposure (Table 3).

Table 2 Associations between electronic cigarette use and asthma symptoms according to cigarette smoking status

\begin{tabular}{|c|c|c|c|c|c|c|}
\hline \multirow[b]{2}{*}{ Cigarette and e-cigarette use } & \multicolumn{2}{|c|}{ Current wheeze } & \multicolumn{2}{|c|}{ Current asthma } & \multicolumn{2}{|c|}{$\begin{array}{l}\text { Current uncontrolled asthma } \\
\text { symptoms }\end{array}$} \\
\hline & $\%$ (n/total) & $\mathrm{aPR}^{*}(95 \% \mathrm{Cl})$ & $\%$ (n/total) & $\mathrm{aPR}^{*}(95 \% \mathrm{Cl})$ & $\%$ (n/total) & $\mathrm{aPR}^{*}(95 \% \mathrm{Cl})$ \\
\hline \multicolumn{7}{|l|}{ Never cigarette smoker } \\
\hline Never e-cigarette use & $21.2(141 / 665)$ & 1.00 (Reference) & $13.4(89 / 665)$ & 1.00 (Reference) & $11.7(78 / 665)$ & 1.00 (Reference) \\
\hline Former e-cigarette use & $30.2(13 / 43)$ & $1.30(0.75-2.23)$ & $16.3(7 / 43)$ & $1.43(0.70-2.92)$ & $14.0(6 / 43)$ & $1.34(0.63-2.86)$ \\
\hline Current e-cigarette use & $31.4(11 / 35)$ & $1.54(1.01-2.45)$ & $25.7(9 / 35)$ & $1.85(1.03-3.41)$ & $22.9(8 / 35)$ & $1.56(0.80-3.06)$ \\
\hline \multicolumn{7}{|l|}{ Former cigarette smoker } \\
\hline Never e-cigarette use & $27.2(28 / 103)$ & $1.26(0.89-1.80)$ & $22.3(23 / 103)$ & $1.67(1.08-2.58)$ & $17.5(18 / 103)$ & $1.42(0.88-2.32)$ \\
\hline Former e-cigarette use & $27.5(19 / 69)$ & $1.24(0.81-1.92)$ & $14.5(10 / 69)$ & $1.11(0.58-2.11)$ & $14.5(10 / 69)$ & $1.18(0.63-2.23)$ \\
\hline Current e-cigarette use & $33.3(24 / 72)$ & $1.52(1.05-2.21)$ & $20.8(15 / 72)$ & $1.71(1.05-2.78)$ & $27.8(20 / 72)$ & $2.28(1.45-3.58)$ \\
\hline \multicolumn{7}{|l|}{ Current cigarette smoker } \\
\hline Never e-cigarette use & $36.4(16 / 44)$ & $1.64(1.06-2.55)$ & $20.5(9 / 44)$ & $1.73(1.01-3.21)$ & $13.6(6 / 44)$ & $1.01(0.43-2.38)$ \\
\hline Former e-cigarette use & $36.7(18 / 49)$ & $1.57(1.02-2.43)$ & $22.5(11 / 49)$ & $1.89(1.05-3.43)$ & $26.5(13 / 49)$ & $2.34(1.38-3.99)$ \\
\hline Current e-cigarette use & $41.9(111 / 265)$ & $1.87(1.44-2.42)$ & $26.0(69 / 265)$ & $1.92(1.33-2.76)$ & $24.9(66 / 265)$ & $1.97(1.35-2.88)$ \\
\hline
\end{tabular}

$a P R$ adjusted prevalence ratio, $\mathrm{Cl}$ confidence interval

* Adjusted for sex, age, exposure to household secondhand smoke, exposure to household secondhand aerosols from electronic cigarettes, and exposure to secondhand smoke and/or secondhand aerosols from electronic cigarettes in public places 
Table 3 Associations between frequency of exposure to household secondhand aerosols (SHA) from electronic cigarettes in the past 7 days and asthma symptoms

\begin{tabular}{|c|c|c|c|c|c|c|}
\hline \multirow[b]{2}{*}{$\begin{array}{l}\text { Household secondhand } \\
\text { aerosol exposure in past } 7 \text { days }\end{array}$} & \multicolumn{2}{|c|}{ Current wheeze } & \multicolumn{2}{|c|}{ Current asthma } & \multicolumn{2}{|c|}{$\begin{array}{l}\text { Current uncontrolled asthma } \\
\text { symptoms }\end{array}$} \\
\hline & $\%$ (n/total) & $\mathrm{aPR}^{*}(95 \% \mathrm{Cl})$ & $\%$ (n/total) & $\mathrm{aPR}^{*}(95 \% \mathrm{Cl})$ & $\%$ (n/total) & $\mathrm{aPR}^{*}(95 \% \mathrm{Cl})$ \\
\hline No exposure (0 days) & $24.1(215 / 894)$ & 1.00 (Reference) & $14.1(124 / 894)$ & 1.00 (Reference) & $12.0(107 / 894)$ & 1.00 (Reference) \\
\hline Infrequent exposure ( $1-2$ days) & $30.3(40 / 132)$ & $1.17(0.87-1.58)$ & $22.7(30 / 132)$ & $1.49(1.01-2.23)$ & $18.9(25 / 132)$ & $1.53(1.00-2.33)$ \\
\hline Frequent exposure ( $\geq 3$ days) & $38.8(120 / 309)$ & $1.30(1.04-1.59)$ & $27.2(84 / 309)$ & $1.56(1.13-2.16)$ & $27.8(86 / 309)$ & $1.88(1.35-2.62)$ \\
\hline
\end{tabular}

aPR: adjusted prevalence ratio; $\mathrm{Cl}$ : confidence interval

* Adjusted for sex, age, cigarette smoking status, electronic cigarette use status, exposure to household secondhand smoke, and exposure to secondhand smoke and/ or secondhand aerosols from electronic cigarettes in public places

\section{Discussion}

This school-based cross-sectional study aimed to assess associations between e-cigarette use and exposure to household SHA from e-cigarettes with asthma symptoms among a sample of adolescents in Kuwait. The findings indicated that e-cigarette use was associated with increased prevalence of asthma symptoms independent of combustible cigarette use, exposure to household and public places SHS and SHA from e-cigarettes, sex, and age. Moreover, our results showed that frequency of exposure to household SHA from e-cigarettes was associated with asthma symptoms independent of combustible cigarette use, e-cigarette use, exposure to household SHS, exposure to public places SHS/SHA, sex, and age. To our knowledge the finding of associations between exposure to household SHA from e-cigarettes and asthma symptoms is novel. These findings highlight the potential adverse respiratory effects of primary use of e-cigarettes as well as passive exposure to their aerosols among adolescents.

The current study identified positive associations between current e-cigarette use with current wheeze and current asthma that were independent of combustible cigarette use and other covariates. These results are consistent with prior cross-sectional studies that showed associations between e-cigarette use and respiratory symptoms among both adolescents [20-25] and adults [26-29]. The causal inference of such associations is further strengthened by results of a recent longitudinal study that showed e-cigarette use is associated with incident respiratory disease [30]. The effect size of the association between e-cigarette use and current asthma in this report $(\mathrm{aPR}=1.85,95 \% \mathrm{CI} 1.03-3.41)$ is similar to the effect sizes identified by prior studies, such as reports by Schweitzer et al. (current asthma vs. never asthma: adjusted odds ratio $[\mathrm{aOR}]=1.48,95 \%$ CI $1.26-1.74$ ) [20] and Bhatta and Glantz (current asthma vs. no current asthma: $\mathrm{aOR}=1.56,95 \%$ CI $1.10-2.22$ ) [30]. Moreover, the highest increase in the prevalence of asthma symptoms was observed among dual users of combustible cigarettes and e-cigarettes, which is in line with previous studies [27, 28]. Hence, we demonstrated that use of e-cigarettes alone associated with increased asthma symptoms, and the burden of these symptoms is further increased when e-cigarette use is combined with combustible cigarette use among the vulnerable population of adolescents. Also, it is important to note that current cigarette smoking showed significant associations with asthma symptoms independent of e-cigarette use status. Hence, further highlighting the established harmful effects of cigarette smoking on respiratory health.

Furthermore, we demonstrated associations between frequency of exposure to household SHA from e-cigarettes with asthma symptoms that were independent of combustible cigarette use, e-cigarette use, exposure to household SHS, exposure to public places SHS/SHA, sex, and age. Although a large body of literature exists on the detrimental health effects of SHS exposure on children and non-smoker adults [36-38], a limited number of population-based studies have assessed the effects of exposure to SHA from e-cigarettes on respiratory health. An experimental study showed that passive exposure to e-cigarette aerosols among non-smoking adults associated with multiple adverse symptoms, including ocular, nasal, and throat-respiratory symptoms [39]. Moreover, Bayly et al. showed that among adolescents with asthma diagnosis, exposure to SHA from e-cigarettes was associated with higher odds of experiencing asthma exacerbations $(\mathrm{aOR}=1.27,95 \% \mathrm{CI} 1.11-1.47)$ [31]. In the current report we demonstrated that frequent exposure ( $\geq 3$ days in past 7 days) to household SHA from e-cigarettes was associated with increased prevalence of current wheeze, current asthma, and current uncontrolled symptoms of asthma. Up to our knowledge, such results are novel and further highlight the adverse health effects of passive exposure to e-cigarettes aerosols on respiratory health. 
Given that exposure to SHA is on the rise [40], community-level public health strategies are needed to address e-cigarette use.

Experimental and clinical research have demonstrated the biological plausibility of the effects of e-cigarettes on respiratory health [18]. In vitro experiments have shown that exposing human/animal bronchial epithelial cells to e-liquids/e-cigarettes aerosols is associated with wide array of effects, including altered membrane fluidity, impaired barrier function, increased cell apoptosis, decreased cell proliferation, increased levels of cellular stress, increased cellular toxicity, and increased secretion of inflammatory cytokines [15, 18, 41, 42]. Similarly, animal model investigations showed a range of effects of e-cigarettes, such as increased airway hyper-reactivity; distal airway enlargement; increased lung mucin production, and increased inflammatory cytokines $[15,18$, $41,42]$. In humans, exposing healthy never smokers to acute e-cigarette aerosols (i.e., approximately equivalent to smoking 2 combustible cigarettes) was associated with altered biology of lung cells, including the small airway epithelium, alveolar macrophages, and circulating endothelial microparticles [43]. Moreover, a study conducted in apparently healthy men who never used combustible cigarettes showed that e-cigarette use was associated with impaired lung function parameters [44]. Therefore, accumulating evidence indicate that e-cigarette use is not benign and is potentially associated with respiratory disease.

A strength to our study is the enrollment of a schoolbased random and representative sample of adolescents (11th and 12th grade high school students) from all governorates of Kuwait. Moreover, adapting questions from the standardized NYTS questionnaire allowed us to follow similar definitions used by the NYTS studies $[1,2]$. Similarly, adapting questions and definitions used in by ISAAC further strengthened our outcome ascertainments [32, 33]. Nevertheless, our study has some limitations. Although we have used the standardized ISAAC questionnaire, self-reporting of asthma symptoms may introduce information bias. Prior studies have shown that the ISAAC questionnaire has good validity in ascertaining asthma symptoms when compared to physician diagnosis of asthma (sensitivity: 0.85 [95\% CI 0.73-0.93], specificity: 0.81 [95\% CI 0.76-0.86]) [45] and anti-asthmatic medication reimbursement data (sensitivity: 0.98 [95\% CI 0.92-0.99], specificity: 0.98 [95\% CI 0.97-0.98]) [46]. Moreover, asthma defined in a similar manner to our "current asthma" variable was reported to be associated with lower lung function parameters [47, 48]; hence, further validating the asthma definition used in this report. The estimated prevalence of current wheeze $(28.3 \%)$ in this report is similar to a prior estimate of wheeze among children aged 13/14 years in Kuwait (25.9\%) [49]. Similarly, our estimated prevalence of current asthma (18.0\%) is similar to the prevalence estimate of asthma among 18-year old Isle of Wight birth cohort participants (17.7\%), which used a comparable asthma definition [50]. Also, our estimated effect sizes relating e-cigarette use to asthma symptoms are similar to estimates from prior studies [20,30]. Hence, we anticipate that the effect of information bias, if any, is minimal. Lack of detailed information on adherence to medication among participants with asthma is a further limitation to our study. Moreover, selection bias could also be a concern in cross-sectional studies; however, the possibility of selection bias affecting the results of our study is low because of the high response proportion. Another limitation to our study is the lack of confirmatory information on the extent of household SHA exposure. For instance, information on whether the participants were directly exposed to household SHA (i.e., being in the same room as the e-cigarette user) and the duration of their exposure would have increased the validity of our SHA exposure variable. An inherent limitation of cross-sectional studies is the inability to assess temporal sequence of events. It is also essential to indicate that our analysis aimed to assess concurrent associations rather than to determine temporal and causal associations.

\section{Conclusions}

The findings of this study add to existing knowledge by demonstrating associations between e-cigarette use and exposure to household SHA from e-cigarettes with asthma symptoms among adolescents. The finding of associations between passive exposure to e-cigarettes aerosols and asthma symptoms adds a new perspective and highlights the importance of increasing awareness about the potential harmful effects of such passive exposure, particularly among children and adolescents. Moreover, public health strategies should be placed to curb the ever increasing use of e-cigarettes among adolescents and denormalize and prohibit the use of e-cigarettes in indoor places to reduce passive exposure. Ultimately, comprehensive public health policies and strategies that aim to reduce tobacco use, including e-cigarettes, among adults and adolescents in the population should be developed and implemented.

\section{Abbreviations}

E-cigarettes: Electronic cigarettes; SHA: Secondhand aerosol; SHS: Secondhand smoke; Cl: Confidence interval; PR: Prevalence ratio; NYTS: National youth tobacco survey; ISAAC: International Study of Asthma and Allergies in Childhood; EVALI: E-cigarette, or vaping, product use-associated lung injury; THC: Tetrahydrocannabinol. 


\section{Acknowledgements}

We would like to thank the study participants for their time and cooperation. Additionally, we sincerely appreciate the cooperation, coordination, and assistance of the staff at the different schools.

\section{Authors' contributions}

AN and AR drafted the manuscript, analyzed and interpreted the data, and contributed to data collection. DR, AS, MA, MH, WM, and AE contributed to data collection and interpretation. AHZ contributed to data analysis and interpretation and drafting the manuscript. All authors have contributed to conceiving and designing the study. All authors critically revised the manuscript for important intellectual content. All authors read and approved the final manuscript.

\section{Funding}

None.

\section{Availability of data and materials}

The datasets used and analyzed during the current study are available from the corresponding author on reasonable request.

\section{Ethics approval and consent to participate}

The study was approved by the Health Sciences Center Ethics Committee for Student Research at Kuwait University (No. 750). Written informed consent was taken from each student. As per the waiver obtained from the Ethics Committee, no consents were sought from the parents.

\section{Consent for publication}

Not applicable.

\section{Competing interests}

The authors declare that they have no competing interests.

\section{Author details}

${ }^{1}$ Faculty of Medicine, Kuwait University, Kuwait City, Kuwait. ${ }^{2}$ Department of Community Medicine and Behavioral Sciences, Faculty of Medicine, Kuwait University, Kuwait City, Kuwait.

Received: 12 February 2020 Accepted: 9 November 2020 Published online: 16 November 2020

\section{References}

1. Cullen KA, Gentzke AS, Sawdey MD, Chang JT, Anic GM, Wang TW, et al. e-Cigarette use among youth in the United States, 2019. JAMA. 2019:322:2095-103.

2. Gentzke AS, Creamer M, Cullen KA, Ambrose BK, Willis G, Jamal A, et al. Vital signs: tobacco product use among middle and high school students-United States, 2011-2018. MMWR Morb Mortal Wkly Rep. 2019:68:157-64

3. Hammond D, Reid JL, Rynard VL, Fong GT, Cummings KM, McNeill A, et al. Prevalence of vaping and smoking among adolescents in Canada, England, and the United States: repeat national cross sectional surveys. BMJ. 2019:365:12219.

4. Yoong SL, Stockings E, Chai LK, Tzelepis F, Wiggers J, Oldmeadow C, et al. Prevalence of electronic nicotine delivery systems (ENDS) use among youth globally: a systematic review and meta-analysis of country level data. Aust N Z J Public Health. 2018;42:303-8.

5. Soneji S, Barrington-Trimis JL, Wills TA, Leventhal AM, Unger JB, Gibson LA et al. Association between initial use of e-cigarettes and subsequent cigarette smoking among adolescents and young adults: a systematic review and meta-analysis. JAMA Pediatr. 2017;171:788-97.

6. Goldenson NI, Leventhal AM, Stone MD, McConnell RS, Barrington-Trimis $J$ L. Associations of electronic cigarette nicotine concentration with subsequent cigarette smoking and vaping levels in adolescents. JAMA Pediatr. 2017;171:1192-9.

7. Berry KM, Fetterman JL, Benjamin EJ, Bhatnagar A, Barrington-Trimis $J L$, Leventhal AM, et al. Association of electronic cigarette use with subsequent initiation of tobacco cigarettes in US youths. JAMA Netw Open. 2019;2:e187794.

8. Best C, Haseen F, Currie D, Ozakinci G, MacKintosh AM, Stead M, et al. Relationship between trying an electronic cigarette and subsequent cigarette experimentation in Scottish adolescents: a cohort study. Tob Control. 2017;27:373-8.

9. U.S. Department of Health and Human Services: the health consequences of smoking: 50 years of progress. A Report of the Surgeon General. Atlanta, GA: U.S. Department of Health and Human Services, Centers for Disease Control and Prevention, National Center for Chronic Disease Prevention and Health Promotion, Office on Smoking and Health; 2014.

10. Chadi N, Schroeder R, Jensen JW, Levy S. Association between electronic cigarette use and marijuana use among adolescents and young adults: a systematic review and meta-analysis. JAMA Pediatr. 2019;173:e192574.

11. Audrain-McGovern J, Stone MD, Barrington-Trimis J, Unger JB, Leventhal AM. Adolescent e-cigarette, Hookah, and conventional cigarette use and subsequent marijuana use. Pediatrics. 2018;142:e20173616.

12. Blount BC, Karwowski MP, Shields PG, Morel-Espinosa M, Valentin-Blasini L, Gardner M, et al. Vitamin E acetate in bronchoalveolar-lavage fluid associated with EVALI. N Engl J Med. 2020;382:697-705.

13. Taylor J, Wiens T, Peterson J, Saravia S, Lunda M, Hanson K, et al. Characteristics of e-cigarette, or vaping, products used by patients with associated lung injury and products seized by law enforcement-Minnesota, 2018 and 2019. MMWR Morb Mortal Wkly Rep. 2019;68:1096-100.

14. Ferkol TW, Farber HJ, La Grutta S, Leone FT, Marshall HM, Neptune E, et al. Electronic cigarette use in youths: a position statement of the Forum of International Respiratory Societies. Eur Respir J. 2018;51:1800278.

15. Dinakar C, O'Connor GT. The health effects of electronic cigarettes. N Engl J Med. 2016;375:1372-81.

16. Bals R, Boyd J, Esposito S, Foronjy R, Hiemstra PS, Jimenez-Ruiz CA, et al. Electronic cigarettes: a task force report from the European Respiratory Society. Eur Respir J. 2019;53:1801151.

17. Ballbe M, Martinez-Sanchez JM, Sureda X, Fu M, Perez-Ortuno R, Pascual JA, et al. Cigarettes vs. e-cigarettes: passive exposure at home measured by means of airborne marker and biomarkers. Environ Res. 2014;135:76-80.

18. Gotts JE, Jordt SE, McConnell R, Tarran R. What are the respiratory effects of e-cigarettes? BMJ. 2019;366:15275.

19. Glantz SA, Bareham DW. E-cigarettes: use, effects on smoking, risks, and policy implications. Annu Rev Public Health. 2018;39:215-35.

20. Schweitzer RJ, Wills TA, Tam E, Pagano I, Choi K. E-cigarette use and asthma in a multiethnic sample of adolescents. Prev Med. 2017;105:226-31.

21. Cho JH, Paik SY. Association between electronic cigarette use and asthma among high school students in South Korea. PLOS ONE. 2016;11:e0151022.

22. Wang MP, Ho SY, Leung LT, Lam TH. Electronic cigarette use and respiratory symptoms in Chinese adolescents in Hong Kong. JAMA Pediatr. 2016:170:89-91.

23. Kim SY, Sim S, Choi HG. Active, passive, and electronic cigarette smoking is associated with asthma in adolescents. Sci Rep. 2017:7:17789.

24. McConnell R, Barrington-Trimis JL, Wang K, Urman R, Hong H, Unger J, et al. Electronic cigarette use and respiratory symptoms in adolescents. Am J Respir Crit Care Med. 2017;195:1043-9.

25. Choi K, Bernat D. E-cigarette use among Florida youth with and without asthma. Am J Prev Med. 2016;51:446-53.

26. Osei AD, Mirbolouk M, Orimoloye OA, Dzaye O, Uddin SMI, Dardari ZA, et al. The association between e-cigarette use and asthma among never combustible cigarette smokers: behavioral risk factor surveillance system (BRFSS) 2016 \& 2017. BMC Pulm Med. 2019;19:180.

27. Li D, Sundar IK, McIntosh S, Ossip DJ, Goniewicz ML, O'Connor RJ, et al. Association of smoking and electronic cigarette use with wheezing and related respiratory symptoms in adults: cross-sectional results from the Population Assessment of Tobacco and Health (PATH) study, wave 2. Tob Control. 2020;29:140-7.

28. Hedman L, Backman H, Stridsman C, Bosson JA, Lundback M, Lindberg A, et al. Association of electronic cigarette use with smoking habits, demographic factors, and respiratory symptoms. JAMA Netw Open. 2018;1:e180789.

29. Wills TA, Pagano I, Williams RJ, Tam EK. E-cigarette use and respiratory disorder in an adult sample. Drug Alcohol Depend. 2019;194:363-70. 
30. Bhatta DN, Glantz SA. Association of e-cigarette use with respiratory disease among adults: a longitudinal analysis. Am J Prev Med. 2020;58:182-90.

31. Bayly JE, Bernat D, Porter L, Choi K. Secondhand exposure to aerosols from electronic nicotine delivery systems and asthma exacerbations among youth with asthma. Chest. 2019;155:88-93.

32. Asher MI, Keil U, Anderson HR, Beasley R, Crane J, Martinez F, et al. International Study of Asthma and Allergies in Childhood (ISAAC): rationale and methods. Eur Respir J. 1995;8:483-91.

33. Lai CK, Beasley R, Crane J, Foliaki S, Shah J, Weiland S, et al. Global variation in the prevalence and severity of asthma symptoms: phase three of the International Study of Asthma and Allergies in Childhood (ISAAC). Thorax. 2009;64:476-83.

34. Taylor DR, Bateman ED, Boulet LP, Boushey HA, Busse WW, Casale TB, et al. A new perspective on concepts of asthma severity and control. Eur Respir J. 2008;32:545-54

35. Ekerljung L, Bossios A, Lotvall J, Olin AC, Ronmark E, Wennergren G, et al. Multi-symptom asthma as an indication of disease severity in epidemiology. Eur Respir J. 2011;38:825-32.

36. United States. Public Health Service. Office of the Surgeon General.: The health consequences of involuntary exposure to tobacco smoke: a report of the Surgeon General. Rockville, MD: U.S. Dept. of Health and Human Services, Public Health Service, Office of the Surgeon General; 2006.

37. Raghuveer G, White DA, Hayman LL, Woo JG, Villafane J, Celermajer D, et al. Cardiovascular Consequences of Childhood Secondhand Tobacco Smoke Exposure: Prevailing Evidence, Burden, and Racial and Socioeconomic Disparities: A Scientific Statement from the American Heart Association. Circulation. 2016;134:e336-59.

38. Oberg M, Jaakkola MS, Woodward A, Peruga A, Pruss-Ustun A. Worldwide burden of disease from exposure to second-hand smoke: a retrospective analysis of data from 192 countries. Lancet. 2011:377:139-46.

39. Tzortzi A, Teloniatis S, Matiampa G, Bakelas G, Tzavara C, Vyzikidou VK, et al. Passive exposure of non-smokers to E-Cigarette aerosols: sensory irritation, timing and association with volatile organic compounds. Environ Res. 2020;182:108963.

40. Tigova O, Amalia B, Castellano Y, Fu M, Nogueira SO, Kyriakos CN, et al. Secondhand exposure to e-cigarette aerosols among smokers: a crosssectional study in six European countries of the EUREST-PLUS ITC Europe Surveys. Tob Induc Dis. 2018;16:A11.

41. Chun LF, Moazed F, Calfee CS, Matthay MA, Gotts JE. Pulmonary toxicity of e-cigarettes. Am J Physiol Lung Cell Mol Physiol. 2017;313:L193-206.
42. Hiemstra PS, Bals R. Basic science of electronic cigarettes: assessment in cell culture and in vivo models. Respir Res. 2016;17:127.

43. Staudt MR, Salit J, Kaner RJ, Hollmann C, Crystal RG. Altered lung biology of healthy never smokers following acute inhalation of e-cigarettes. Respir Res. 2018;19:78.

44. Meo SA, Ansary MA, Barayan FR, Almusallam AS, Almehaid AM, Alarifi NS, et al. Electronic cigarettes: impact on lung function and fractional exhaled nitric oxide among healthy adults. Am J Mens Health. 2019;13:1557988318806073.

45. Jenkins MA, Clarke JR, Carlin JB, Robertson CF, Hopper JL, Dalton MF, et al. Validation of questionnaire and bronchial hyperresponsiveness against respiratory physician assessment in the diagnosis of asthma. Int J Epidemiol. 1996:25:609-16.

46. Nwaru BI, Lumia M, Kaila M, Luukkainen P, Tapanainen H, Erkkola M, et al. Validation of the Finnish ISAAC questionnaire on asthma against antiasthmatic medication reimbursement database in 5-year-old children. Clin Respir J. 2011;5:211-8.

47. Arshad SH, Hodgekiss C, Holloway JW, Kurukulaaratchy R, Karmaus W, Zhang $\mathrm{H}$, et al. Association of asthma and smoking with lung function impairment in adolescence and early adulthood: the Isle of Wight Birth Cohort Study. Eur Respir J. 2020;55:1900477.

48. Karmaus W, Mukherjee N, Janjanam VD, Chen S, Zhang H, Roberts G, et al. Distinctive lung function trajectories from age 10 to 26 years in men and women and associated early life risk factors - a birth cohort study. Respir Res. 2019;20:98.

49. Behbehani NA, Abal A, Syabbalo NC, Abd Azeem A, Shareef E, Al-Momen J. Prevalence of asthma, allergic rhinitis, and eczema in 13- to 14-year-old children in Kuwait: an ISAAC study. International Study of Asthma and Allergies in Childhood. Ann Allergy Asthma Immunol. 2000;85:58-63.

50. Soto-Ramirez N, Ziyab AH, Karmaus W, Zhang H, Kurukulaaratchy RJ, Ewart S, et al. Epidemiologic methods of assessing asthma and wheezing episodes in longitudinal studies: measures of change and stability. J Epidemiol. 2013;23:399-410.

\section{Publisher's Note}

Springer Nature remains neutral with regard to jurisdictional claims in published maps and institutional affiliations.
Ready to submit your research? Choose BMC and benefit from:

- fast, convenient online submission

- thorough peer review by experienced researchers in your field

- rapid publication on acceptance

- support for research data, including large and complex data types

- gold Open Access which fosters wider collaboration and increased citations

- maximum visibility for your research: over $100 \mathrm{M}$ website views per year

At BMC, research is always in progress.

Learn more biomedcentral.com/submissions 